\title{
EYE INJURIES IN SPORT: AN INCREASING PROBLEM
}

\author{
N. P. JONES, FRCS, DO
}

Manchester Royal Eye Hospital

\begin{abstract}
A prospective study of ocular injuries sustained during sport, was performed from January to June 1987 . A total of 84 eye injuries were seen. Of these, 23 were severe enough to necessitate admission to hospital. These latter accounted for one quarter of all severe eye injuries during this period. Racquet sports caused $42 \%$ of the injuries, and $57 \%$ of the hospital admissions, including two penetrating injuries. The importance of sport in causing eye trauma is increasing. It is crucial to encourage safer play, including the wearing of adequate eye protection.
\end{abstract}

Key words: Eye injury, Eye protection, Racquet sports.

\section{INTRODUCTION}

In recent years changes have occurred in the pattern of ocular trauma, especially for severe injuries. Most notable has been the introduction of seat belt legislation which has dramatically reduced the incidence of penetrating injury (Hall et al, 1985; Cole et al, 1987). The relative importance of sports injuries is greater, yet there is evidence too of a real increase in incidence. To attempt to confirm this, a prospective study of all ocular sports injuries was performed over the six month period of 1st January to 30th June, 1987.

\section{METHODS}

All patients attending the Accident and Emergency Department at the Manchester Royal Eye Hospital with ocular trauma were questioned as to the cause of their injury. All those who were playing a sport at the time were included, and the details of their injury noted. Those patients admitted to hospital were questioned in more detail, including details of the exact circumstances of the injury, experience of the sport, previous ophthalmic problems, and experience of ocular protection. Clinical information was unobtainable for two Casualty patients.

\section{RESULTS}

During the six month period a total of 84 patients sustained eye injuries during sport. Table I shows the sports involved. Of these, $23(27.4 \%)$ required admission to hospital. During these six months a total of 95 patients were admitted owing to trauma of all causes, and thus sports injuries account for $24.2 \%$ of these admissions. Table II shows the sports involved for all those admitted to hospital. Spectacles were being worn in two patients, and contact lenses in four. No patient was wearing adequate eye protection, or had done so in the past.

The mean age of the patients was 22 years with a range of 9 to 68 years. Sixty-three per cent of patients were in the $16-35$ years age groups, and $71(84.5 \%)$ were male. The right eye was involved in $45 \%$ of patients, and the left in $55 \%$. Patients numbers fluctuated throughout the period and Table III shows attendances for each month. Table IV shows the injuries sustained by the 82 patients for whom details were available. Most patients had more than one structure damaged.

Address for correspondence:

Nicholas P. Jones, FRCS, DO, Senior Registrar

Manchester Royal Eye Hospital

Oxford Road

Manchester M13 9WH
TABLE I

Frequency of involvement of each sport.

\begin{tabular}{lcc}
\hline Sport & No. of Patients & (\%) \\
\hline Association football & 23 & $(27.4)$ \\
Squash & 14 & $(16.6)$ \\
Badminton & 12 & $(14.3)$ \\
Tennis & 9 & $(10.7)$ \\
Rugby football & 7 & $($ 8.3) \\
Hockey & 4 & $(4.8)$ \\
Cricket & 4 & $(4.8)$ \\
Basketball & 2 & \\
Golf & 2 & \\
Karate & 2 & $(13.1)$ \\
American football & 1 & \\
Darts & 1 & \\
Rounders & 1 & \\
Swingball & 1 & \\
Volleyball & 1 & \\
\hline Total & TABLE II & \\
\hline
\end{tabular}

Hospital admissions: Frequency of each sport.

\begin{tabular}{lcc}
\hline Sport & No. of Patients & $(\%)$ \\
\hline Football & 8 & $(34.8)$ \\
Badminton & 6 & $(26.1)$ \\
Squash & 5 & $(21.7)$ \\
Tennis & 2 & $(17.4)$ \\
Golf & 1 & \\
Darts & 1 & $(100.0)$ \\
\hline Total & 23 & \\
\hline
\end{tabular}

TABLE III

Attendances for each month.

\begin{tabular}{lcc}
\hline Month & Attendances & $(\%)$ \\
\hline January & 14 & $(16.7)$ \\
February & 21 & $(25.0)$ \\
March & 13 & $(15.5)$ \\
April & 14 & $(16.7)$ \\
May & 9 & $(10.6)$ \\
June & 13 & $(15.5)$ \\
\hline Total & 84 & $(100.0)$
\end{tabular}


TABLE IV

Injuries involved.

\begin{tabular}{lr}
\hline Type of Injury & No. of Patients \\
\hline Periorbital haematoma & 20 \\
Periorbital lacerations & 13 \\
Corneal abrasion/laceration & 25 \\
Frank hyphaema & 16 \\
Microscopic hyphaema & 13 \\
Secondary glaucoma & 6 \\
Significant angle recession & 4 \\
Mydriasis/sphincter rupture & 17 \\
Traumatic uveitis & 14 \\
Vitreous haemorrhage & 4 \\
Commotio retinae & 14 \\
Retinal break & 2 \\
Penetrating injury & 3 \\
Blowout orbital fracture & 3 \\
\hline
\end{tabular}

The reasons for admission were hyphaema (15 patients, $65 \%$ ), penetrating injry (three patients, 13\%), uveitis with glaucoma (2 patients), retinal damage (two patients), and blowout fracture of orbit floor requiring surgery (one patient). For those admitted to hospital, the mean experience at the sport was 8.8 years.

The projectile (the ball or shuttlecock) was responsible for the injury in 51 patients $(62 \%)$, the hitting instrument (bat, stick, club or racquet) was responsible in $10(12 \%)$, and some part of an opponent's body in $21(26 \%)$. Of these 21 , seven were considered by the patients to be deliberate assaults. Five of these occurred during association football.

Squash racquets and badminton accounted for $31 \%$ of all patients, and $48 \%$ of those admitted to hospital (badminton six patients, $26 \%$; squash 5 patients, $22 \%$ ). Two of the three penetrating injuries occurred during these sports (one each). Both these injuries were caused by the racquet, one patient wearing spectacles with glass lenses. One eye was removed owing to the severity of the injury. All injured badminton players were playing doubles, and all those injured by shuttlecocks were standing at the net.

\section{DISCUSSION}

Patterns of injury change with time (Garrow, 1923; Johnston, 1975; Canavan et al, 1980) and legislation, and the introduction of a new seatbelt law has highlighted different causes of eye injury. Despite previous reports of the rise in sports injury (Vinger, 1981; Bell, 1981; MacEwen, 1987 ) it is alarming to find that nearly one quarter of all trauma admissions to this hospital were caused by sport and this must surely be an area for continued attention.

Most injuries seen at an ophthalmic casualty department can be dealt with on an outpatient basis, and more severe injuries requiring admission to hospital are uncommon (Jones et al, 1986; Vernon, 1983). It is therefore notable that $27 \%$ of injuries in this study required inpatient treatment, and this is indicative of the frequent severity of sports eye injuries.

Eye injury has been reported in several sports (Jones et al, 1986; Millar, 1967; Seelanfreund et al, 1976). The relative importance of each sport in this series will doubtless be affected by seasonal factors and the short duration of the survey. However, even allowing for this, racquet sports play a substantial role ( 35 patients, $41.7 \%$ ), as with a previous report (Gregory, 1986), and their dangers have been highlighted in the past (Blonstein, 1975; Easterbrook, 1980). Despite frequent and forceful warnings from the medical profession (Ingram et al, 1973; Barrell et al, 1981; Kennerley Bankes, 1985), squash racquets remains a frequent cause of eye injury. Although previously reported (Chandran, 1974; Kelly, 1987), it would now appear that badminton is becoming an equally frequent and important cause. The shuttlecock has shown itself to be a weapon the equal of a squash ball, and this sport is now deserving of as much attention.

The elimination of eye injury from sport is an unrealistic goal, as certain sports carry with them an intrinsic risk of injury. However, this should not be so for racquet sports, and every effort must be made to stem the rising tide of squash and badminton injuries. There has been no evidence that medical publications have had any effect on the incidence of injury. More widespread publicity of the problems is now necessary. The players must be made aware of the risks involved and every effort must be made to reduce their incidence and severity without removing enjoyment from the sports. It is often said that sports injuries are a particular risk in the novice; that experience at a sport is protection in itself. The data from this series show that this is false and such an illusion should be quashed.

This survey highlights especial risk factors in both badminton and squash, and a realisation of this may allow changes in technique which will reduce the incidence of injury. In badminton, doubles (the more popular game) is more accident-prone. Those at the net are at special risk and should be aware of this and protect the face with the racquet. The player should never look back at his or her own partner. In squash, to look back from the front of the court is dangerous, as is following the opponent into the court corner.

Such changes in themselves are inadequate. Proper eye protection is important and should be encouraged. It has been proven to be effective (Vinger, 1981; Pashby, 1985). Contact lenses offer no protection and may complicate an injury. Glass spectacle lenses are dangerous and should never be worn by sportsmen. If refractive correction must be worn then it should ideally be incorporated into polycarbonate protective spectacles.

\section{ACKNOWLEDGEMENTS}

I am grateful to the consultant staff at Manchester Royal Eye Hospital for permission to report on their patients.

\section{References}

Barrell, G. V., Cooper, P. J., Elkington, A. R., MacFayden, J. M., Powell, R. G. and Tormey, P., 1981 "Squash ball to eye ball". Br.Med.J. 283: 893-5.

Bell, J. A., 1981 "Eye trauma in sports: a preventable epidemic". JAMA 246: 156.

Blonstein, J. L., 1975 "Eye injuries in sport with particular reference to squash and badminton". Practitioner 215: 208-9.

Canavan, Y. M., O'Flaherty, M. J., Archer, D. B. and Elwood, J. H., 1980 “A 10year survey of eye injuries in Northern Ireland 1967-1976". Brit.J. Ophthalmol. 64: 618-625.

Chandran, S., 1974 "Ocular hazards of playing badminton". Brit.J.Ophthalmol. 58: 757-60.

Cole, M. D., Clearkin, L., Dabbs, T. and Smerdon, D., 1987 "The seat belt law and after". Brit.J.Ophthalmol. 71: 436-440.

Easterbrook, M., 1980 "Eye injuries in racquet sports: a continuing problem". Can.Med.Assoc.J. 123: 268-9.

Garrow, A., 1923 "A statistical enquiry into 1000 cases of eye injuries". Br.J.Ophthalmol. 7: 65-80.

Gregory, P. T. S., 1986 "Sussex Eye Hospital sports injuries". Br.J.Ophthalmol. 70: 748-50. 
Hall, N. F., Denning, A. M., Elkington, A. R. and Cooper, P. J., 1985 "The eye and the seat belt in Wessex". Brit.J.Ophthalmol. 69: 317-19.

Ingram, D. V. and Lewkonia, I., 1973 "Ocular hazards of playing squash rackets". Brit.J.Ophthalmol. 57: 663-6.

Johnston, S. S., 1975 "The changing pattern of injury". Trans.Ophthalmol. Soc.UK 95: 307-310

Jones, N. P., Hayward, J. M., Khaw, P. T., Claoué, C. M. P. and Elkington, A. R. 1986 "Function of an "accident and emergency" department: results of a six month survey". Brit.Med.J. 292: 188-90.

Jones, N. P. and Tullo, A. B., 1986 "Severe eye injuries in cricket". Brit.J.Sports Med. 20: 178-9.

Kelly, S. P., 1987 "Serious eye injury in badminton players". Brit.J. Ophthalmol. 71: 746-7.
Kennerley Bankes, J. L., 1985 "Squash rackets: a survey of eye injuries in England". Brit.Med.J. 291: 1539.

MacEwen, C. J., 1987 "Sport associated eye injury: a casualty department survey". Brit.J.Ophthalmol. 71: 701-5.

Millar, C. T., 1967 "Golfing eye injuries". Am.J.Opthalmol. 64: 741.

Pashby, T., 1985 "Eye injuries in Canadian amateur hockey". Can.J. Ophthalmol. 20: 2-4.

Seelanfreund, M. H. and Freilich, D. B., 1976 "Rushing the net and retinal detachment". JAMA 235: 2723-5.

Vernon, S. A., 1983 "Analysis of all new cases seen in a busy regional centre ophthalmic casualty department during 24-week period". J.Royal Soc. Med. 76: 279-282.

Vinger, P. F., 1981 "Sports eye injuries. A preventable disease". Ophthalmology 88: 108-112.

\title{
BOOK REVIEW
}

Title:

Author:

Publisher:

\section{HOW IT WAS - ANABOLIC ACTION OF STEROIDS AND REMEMBERENCES}

\author{
C. D. Kochakian
}

The University of Alabama School of Medicine 1984

Price: \$10.95 US 116 pages References

ISBN 6124 00924(B)

This is the autobiography of a biochemist who worked extensively in the field of experimental endocrinology, and whose research was largely instrumental in understanding the action of male sex hormones in controlling primary and secondary sexual development, but also the effect of these substances upon muscle. He was able to show that the anabolic effects of testosterone were a direct action upon the muscle, and, as this effect occurred in animals that had the hypophysis removed, it was not due to the feedback action of the hormone upon the hypothalamus. He assisted in the preparation of anabolic steroids on a large-scale basis, and realised the great benefits these substances could have upon the well-being of people suffering from malignant and other wasting diseases. Although the discoverer of the anabolic actions of androgens, he does not, anywhere in his book, discuss their possible role in the unethical or illegal use in muscle building to give an unfair advantage to so-called sportsmen. In a letter to me, the author wrote "Since there seems to be a continued, and indeed growing interest of anabolic steroids in sport, it seems appropriate to acquaint your readers with a historical review of the discovery and the delineation of the anabolic action of steroids."

Apart from the account of the development and use of one class of steroids, the book has several lessons that could well be learned by other research workers. His early experiments in isolating hormones involved inexpensive but troublesome techniques such as the evaporation of gallons of urine to obtain enough hormone to use on one or two experimental animals. Evaporation was performed by placing shallow dishes over a heat source consisting of 100 watt light bulbs placed in discarded fruit tins, and metabolic studies done the hard way in Benedict or Haldane oxygen/carbon dioxide absorption methods, - echoes of the 1940's in undergraduate physiology laboratories. One important lesson he learnt was that results in one species of animal were not always the same in another; - rats are not large mice, and the renotrophic and androgenic effects of testosterone give different effects in rats compared with guinea pigs and hamsters, the latter species showing a greater anabolic effect. It is therefore dangerous to transfer results directly to man without a lot of extra work and careful follow-up. From the viewpoint of experimental biological science, this book has a place in the shelves of the research library or the departmental bookshelf, whether the field of study is into hormonal control, or any other branch of biology, connected with sport or not. The review copy will be available among the BASM's book collection in the library of the London Institute of Sports Medicine.

Henry E. Robson

\section{BOOK REVIEW}

Title:

Author:

\section{AIDS TO HUMAN OSTEOLOGY (SEVENTH EDITION)}

Publisher:

\author{
Jack Joseph
}

Baillière Tindall

Price: $€ 3.95$

203 pages

51 figs.

Soft cover Index

ISBN 0702011576

Considering the First Edition of this small text was published in 1920, with the Seventh Edition in 1963 and revised and reprinted in 1976 and 1986 it really has stood the test of time and surely has been an invaluable crammer to generations of medical students hovering on the brink of the second MB examinations.

It contains generous accurate diagrams, a useful index and an updated glossary, while it has no pretensions at being other than its stated title.

The modern student of anatomy may prefer the more recent, larger, colourful texts but would be hard pressed to get better value for money. 